Spat i ot empor al di stribut i on of ther mal pl asma temper at ure and precursor for mat i on in a torch dur ing Ti 02 nanopowder synt hesi s

\begin{tabular}{|l|l|}
\hline 著者 & $\begin{array}{l}\text { Kodama Naot o, Tanaka Yasunor i, Ki t a K, } \\
\text { I shi saka Y., Uesugi Yoshi hi ko, I shi j i ma } \\
\text { Tat suo, Sueyasu S., Nakamur a Kei t ar o }\end{array}$ \\
\hline $\begin{array}{l}\text { j our nal or } \\
\text { publ i cat i on t i t l e }\end{array}$ & Pl asma Sour ces Sci ence and Technol ogy \\
\hline vol une & 26 \\
\hline number & 7 \\
\hline page r ange & 75008 \\
\hline year & $2017-06-26$ \\
\hline URL & ht t p: //hdl . handl e. net /2297/48439 \\
\hline
\end{tabular}




\title{
Spatiotemporal distribution of thermal plasma temperature and precursor formation in a torch during $\mathrm{TiO}_{2}$ nanopowder synthesis.
}

\author{
Naoto Kodama $\dagger$, Yasunori Tanaka $\dagger$, K Kita, Y Ishisaka, \\ Y Uesugi, T Ishijima, S Sueyasuł, K Nakamurał \\ Faculty of Electrical Engineering and Computer Science, Kanazawa University, \\ Kakuma, Kanazawa 920-1192, JAPAN \\ $\ddagger$ Research Center for Production \& Technology, Nisshin Seifun Group Inc., 5-3-1 \\ Tsurugaoka, Fujimino 356-8511, JAPAN \\ E-mail: n_kodama@stu.kanazawa-u.ac.jp, tanaka@ec.t.kanazawa-u.ac.jp
}

\begin{abstract}
The spatiotemporal distribution of Ti excitation temperature $\left(T_{\mathrm{ex}}^{\mathrm{Ti}}\right)$ was determined from two-dimensional optical emission spectroscopy (2-D OES) during $\mathrm{TiO}_{2}$ nanopowder synthesis using an inductively coupled thermal plasma (ICTP) torch. The Ti feedstock powder was injected intermittently into the ICTP torch to elucidate the evapouration of the feedstock and the formation of atomic vapour, precursor molecules, and particle nuclei dynamically. The spectroscopic observation results revealed that $T_{\mathrm{ex}}^{\mathrm{Ti}}$ was estimated as $2500-4000 \mathrm{~K}$ around the central axis of the ICTP torch, and as more than $4500 \mathrm{~K}$ in the off-axis region. In the on-axis region, $\mathrm{TiO}$ was detected with high radiation intensity in the lower temperature region. These results showed that $\mathrm{TiO}$ molecules are formed only in low temperature region around the central axis of the ICTP torch. In addition, TiO molecular density could be high especially in downstream region at central axis of the ICTP torch.
\end{abstract}

PACS numbers: 52.70.-m, 52.50.Dg, 52.70.Kz, 52.80.Pi, 61.43.Gt, 68.55.A-

Submitted to: Plasma Sources Sci. Technol.

$\dagger$ To whom correspondence should be addressed (n_kodama@stu.kanazawa-u.ac.jp, tanaka@ec.t.kanazawa-u.ac.jp) 


\section{Introduction}

Nanopowders and nanoparticles (NPs) are receiving great attention as next-generation materials because of their unique physical, chemical, and optical properties compared to their bulk properties. Therefore, NPs are used in diverse fields: electronics, medicine, energy, and the environment. For example, titanium dioxide nanoparticles $\left(\mathrm{TiO}_{2} \mathrm{NPs}\right)$ is used as a photocatalyst [1], and in photonic crystals [2], photovoltaic cells [3], and gas sensors [4]. In addition, metallic-ion doped $\mathrm{TiO}_{2} \mathrm{NPs}$ are anticipated for use as visible light-active photocatalysts [5]-[7], and as biomedical materials in ointments for atopic dermatitis [8, 9]. Especially for biomedical applications, prevention of contamination in NPs is extremely important because even slight impurities of countable atoms or molecules can alter the NP properties and damage human skin. Therefore, a highpurity synthesis process of NPs with high production efficiency is eagerly sought for progress of nano-technologies.

Various NP synthesis methods have been developed to date. Different thermal plasma torches have been applied in these methods to fabricate nanomaterials including NPs [10]. Among these NP synthesis methods using thermal plasmas, inductively coupled thermal plasma (ICTP) presents some great benefits for NP fabrication [11][18]. One salient benefit of ICTP methods is that ICTP can produce a high-temperature and high-chemical activity field with no impurity from electrodes. In actuality, it requires no electrodes to sustain thermal plasmas. A second important benefit is that the ICTP method can use not only liquid and gas materials but also solid materials as a feedstock material. This feature extends its applicable range for NPs of various types. Another feature is that it can offer one-step, direct processing with much shorter processing time for NP synthesis. The ICTP method can evaporate the feedstock fed to produce atoms in the high-temperature ICTP. Then the evaporated material is cooled to produce NPs. This method can also produce not only pure-metallic NPs but also oxide or nitride NPs by adopting specified reactive gases for processing. Nevertheless, the conventional ICTP method also presents some shortcomings, including poor size control and low production efficiency. Therefore, the alleviation of these shortcomings suggests challenging work for the goal of wider use of ICTP methods in future applications.

The authors have developed a unique and original method of large-scale NP synthesis using pulse-modulated induction thermal plasma (PMITP) with timecontrolled feeding of a feedstock (TCFF) [19]-[22]. We designate this method as 'PMITP+TCFF method'. The PMITP was developed in our group to control the hightemperature and chemical activity fields in thermal plasmas in the time domain using amplitude modulation of the coil-current $[23,24]$. In addition, we contrived the TCFF method for more effective NP fabrication. The TCFF method was applied to control timing of the feedstock injection into the ICTP torch. In the PMITP+TCFF method, feedstock powder is intermittently injected synchronously with coil-current modulation of PMITP [21, 22]. This PMITP + TCFF method provides effective evaporation of feedstock. Then effective cooling of the evaporated materials is done for efficient 
nucleation of NPs. In our earlier work, the $20 \mathrm{~kW}$ PMITP-TCFF method was adopted for pure- $\mathrm{TiO}_{2} \mathrm{NPs}$ and $\mathrm{Al}^{3+}$-doped $\mathrm{TiO}_{2} \mathrm{NP}$ syntheses. In this work, pure- $\mathrm{TiO}_{2} \mathrm{NPs}$ with mean particle diameter of approximately $43 \mathrm{~nm}$ and $\mathrm{Al}^{3+}$-doped $\mathrm{TiO}_{2} \mathrm{NPs}_{\text {with }}$ mean particle diameter of approximately $67 \mathrm{~nm}$ were synthesized with a high production rate of more than approximately $400-500 \mathrm{~g} \mathrm{~h}^{-1}[25,26]$. These production rates at input power of $20 \mathrm{~kW}$ were several tens of times higher than those of conventional methods using thermal plasmas.

One key point for enhancement of production efficiency is to elucidate NP formation mechanisms including feedstock evaporation processes and precursor molecule formation processes. For this purpose, many numerical simulations have been conducted for various kinds of NP synthesis using an ICTP torch to clarify NP formation processes including feedstock evaporation, precursor formation, nucleation and NP growth processes [27][29]. However, few reports have described investigation of NP synthesis processes based on spatial and temporal measurements for the ICTP torch during NP synthesis.

We have been investigating these processes during pure- $\mathrm{TiO}_{2} \mathrm{NP}$ synthesis using the ICTP mainly with a two-dimensional optical emission spectroscopic (2-D OES) system. Results showed that spatiotemporal information of $\mathrm{Ti}$ I and $\mathrm{TiO}$ spectral radiation intensities were detected with this 2-D OES system [30]. From those results, fundamental information of $\mathrm{Ti}$ feedstock evaporation and precursor $\mathrm{TiO}$ formation and these transportation processes were inferred during $\mathrm{TiO}_{2} \mathrm{NP}$ synthesis in the nonmodulated ICTP torch with single-shot powder injection [31]. However, the temperature distribution in the ICTP torch has not yet been investigated. The temperature is a crucial parameter for determining NP nucleation processes.

This paper presents estimation results on 2-D temperature distribution in the plasma torch during $\mathrm{TiO}_{2}$ nanopowder synthesis. Almost single-shot feedstock powder injection was applied to the non-modulated ICTP torch in this experiment. For this estimation, the Ti excitation temperature $T_{\mathrm{ex}}^{\mathrm{Ti}}$ distribution was estimated using the twoline method for two Ti I atomic spectral lines. The spatial and temporal change in the $T_{\text {ex }}^{\mathrm{Ti}}$ was evaluated in the plasma torch during $\mathrm{TiO}_{2} \mathrm{NP}$ synthesis. Result showed that the Ti excitation temperature is higher at off-axis region in the ICTP torch, while it is lower at central axis region with strong $\mathrm{TiO}$ radiation intensity. These results suggest that $\mathrm{TiO}$ molecules are formed only at lower temperature region around central axis region in the ICTP torch.

\section{Principle of 2-D OES system}

This section describes the principle of 2-D OES system used in our experiments. Figure 1 shows schematic diagram of the 2-D OES system. This OES system consists of an imaging spectrometer, an objective lens and a collimator lens in front of the spectrometer, and a high speed video camera behind the spectrometer. This type of the imaging spectroscopic system is often called "Monochromatic imaging spectrometer (MIS)" [32, 33]. The MIS is based on the idea using a Czerny-Turner spectrometer. The 
Czerny-Turner spectrometer has an entrance slit, a spherical mirror (a), a diffraction grating, a spherical mirror (b), and an exit slit. Using this spectrometer, a 2-D monochromatic image can be obtained as follows:

(i) A image from a light source is captured by an objective lens.

(ii) This image through the objective lens is collimated by a collimator lens (a) located in front of the entrance slit of the spectrometer. Then, a part of the collimated light is fed into the spectrometer through the slit.

(iii) From the light fed from the entrance slit, the image is reformed on the focal plane in vicinity of the diffraction grating by the spherical mirror (a), because the distance between the entrance slit and the grating is equal to the focal distance of the spherical mirror (a). Then, this focal image is dispersed in different wavelengths by the diffraction grating.

(iv) The dispersed image is re-collimated by the spherical mirror (b).

(v) The re-collimated light at a specified wavelength can pass through the exit slit. This re-collimated monochromatic light contains information on the 2-D image.

(vi) If a camera lens is located outside of the exit slit, a monochromatic 2-D image at the specified wavelength can be obtained on the focal plane of the camera lens. Thus, a 2-D monochromatic image can be captured by an 2-D imaging sensor placed on the focal plane.

In this system, the entrance slit works only as an aperture of the spectrometer. The wavelength resolution is determined by width of the exit slit and the type of the diffraction grating adopted. Main advantages of this 2-D OES system are a high wavelength resolution $(\sim 0.2-0.8 \mathrm{~nm})$, and setting observation wavelength variable, rather than the conventional band-bass interference filters. In general, band-pass interference filters have been often used for 2-D OES with a high-speed video camera or an ICCD. However, the wavelength resolution of the filter is low like as few $\mathrm{nm}$ to few tens nm, and we cannot change the observation wavelength of the filter; another filter for another wavelength should be prepared. In contrast, the 2D-OES system based on MIS has a high wavelength resolution, and freedom degree for observation wavelength. Meanwhile, this system loses much of light from the light source at the entrance slit of the spectrometer. Nevertheless, this light loss is not a serious problem in the present observation because a thermal plasma of interest has an extremely high radiation intensity. Thus, the 2-D OES system based on MIS is greatly useful for investigation of thermal plasma processing.

\section{Experimental}

\subsection{Experimental setup}

The experimental setup was the same as that reported in our earlier work [26]. Figure 2 shows the non-modulated ICTP torch for $\mathrm{TiO}_{2}$ nanopowder synthesis. This cylindrical- 
type of ICTP torch has two co-axial quartz tubes. The water flows between quartz tubes to cool the inner quartz tube wall. The inner quartz has $70 \mathrm{~mm}$ inner diameter and $370 \mathrm{~mm}$ length; the outer quartz tube has $85 \mathrm{~mm}$ outer diameter. The eightturn induction coil is located around the outer quartz tube. The coil is connected to a matching circuit and inverter power supply to generate an electromagnetic field. Consequently an RF thermal plasma is produced inside the inner quartz tube of the plasma torch. A water-cooled stainless steel feeding tube is inserted from the top of the torch head, located on the central axis of the torch. The outer diameter and inner diameter of the feeding tube are, respectively, $10 \mathrm{~mm}$ and $4 \mathrm{~mm}$. The feedstock can be injected directly into the thermal plasma through the feeding tube from a powder feeder. Between the feeding tube and the powder feeder, a high-speed solenoid valve is installed to control feedstock injection into the thermal plasmas. This solenoid valve can be controlled using a transistor-transistor logic (TTL) signal. Figure 3 depicts an overall view of the experimental system for nanoparticles synthesis, including the ICTP torch, reaction chambers, a collection filter, and a vacuum pump. The reaction chambers and the collection filter are installed downstream of the ICTP torch to collect the synthesized nanopowder. All reaction chamber walls are cooled by water. Details of these experimental apparatuses are available in the literature [26].

\subsection{Experimental conditions}

Table 1 presents the experimental conditions of pure- $\mathrm{TiO}_{2}$ nanopowder synthesis described in the present work. In this experiment, the Ti feedstock was intermittently injected into the non-modulated PMITP torch (i.e. conventional ICTP torch) to investigate the spatiotemporal behaviours of $\mathrm{Ti}$ feedstock vapour and precursor $\mathrm{TiO}$ vapour, and also the temperature and nucleation inside the ICTP torch. The timeaveraged input power from the inverter power supply was fixed at $20 \mathrm{~kW}$. The fundamental frequency of the coil-current was about $304 \mathrm{kHz}$. A mixture gas of Ar and $\mathrm{O}_{2}$ was used as a sheath gas. The total gas flow rate of the sheath gas was fixed at $100 \mathrm{~L} \mathrm{~min}{ }^{-1}$. The gas composition was set to $90 \mathrm{~mol} \% \mathrm{Ar}$ and $10 \mathrm{~mol} \% \mathrm{O}_{2}$. In this experiment, to retain simplicity of the investigation, quenching gas was not supplied to the reaction chamber. The pressure was fixed at 300 Torr (approx. 40 $\mathrm{kPa}$ ) for the inside of torch and reaction chamber. Pure-Ti micro-powder (TILOP-45; Osaka Titanium Technologies Co. Ltd.) was used as the feedstock powder. The mean diameter and the maximum diameter of this feedstock were about $27 \mu \mathrm{m}$ and $45 \mu \mathrm{m}$, respectively. The Ti feedstock was intermittently supplied into the ICTP torch with Ar carrier gas through the solenoid valve and feeding tube. The gas flow rate of Ar carrier gas was fixed at $4 \mathrm{~L} \mathrm{~min}{ }^{-1}$. The feedstock injection was controlled by a high-speed solenoid valve connecting the feeding tube with the rotary powder feeder, as shown in Figure 3. The solenoid valve response time was about $2 \mathrm{~ms}$. The feedstock feeding rate was adjusted to about $4-7 \mathrm{~g} \mathrm{~min}^{-1}$. This feeding rate is lower than those used for large-scale nanopowder synthesis reported in our earlier work [26], but it is higher or 
comparable to that of the conventional ICTP method. This feeding rate condition was selected to investigate fundamental behaviour of the feedstock vapour, precursor $\mathrm{TiO}$ vapour, the temperature distribution and nucleation. The feeding cycle time $\left(t_{\text {valve }}^{\text {cyc }}\right)$ was set to $30 \mathrm{~ms}$, which is much longer than that used in our earlier work [26]. The open $\left(t_{\text {open }}\right) /$ close time $\left(t_{\text {close }}\right)$ of the solenoid valve was adjusted to $8 / 22 \mathrm{~ms}\left(27 \% \mathrm{DF}_{\text {valve }}\right)$. The $\mathrm{DF}_{\text {valve }}$, which was used as a control parameter of the solenoid valve, is defined as $t_{\text {open }} / t_{\text {valve }}^{\text {cyc }}$. In the condition of $27 \% \mathrm{DF}_{\text {valve }}$, the open time was sufficiently shorter than the close time. Therefore the condition of $27 \% \mathrm{DF}_{\text {valve }}$ is regarded as almost a single-shot feedstock feeding. This single-shot feeding was adopted to avoid interaction between feedstock feeding during intermittent feedstock injection [31].

\subsection{Optical emission spectroscopy conditions}

The 2-D OES measurements were conducted using a 2-D OES system (AN-IMC-DD; Anfi Inc.) as presented in figure 4 with a 2-D OES region. This 2-D OES system consists of an objective lens (AF Zoom-Nikkor 80-200 mm f/2.8D ED; Nikon Corp.), an imaging spectrometer (Acton Spectra Pro 2300i; Princeton Instruments, Inc.), and a high-speed video camera (GX-8; NAC Image Technology Inc.). The observation conditions are presented in table 2 . The 2 -D OES region was set to approximately a $47 \times 46 \mathrm{~mm}^{2}$ region below the coil-end, as shown in figure 4 . The imaging spectrometer has a diffraction grating of 1200 grooves $\mathrm{mm}^{-1}$. The wavelength resolution of this system was $0.4 \mathrm{~nm}$. The salient feature of this system is that it can measure the radiation intensity of spectral lines with higher wavelength resolution of $0.4 \mathrm{~nm}$ than those other imaging OES systems using optical interference bandpass filters. In this work, two Ti I spectral lines were observed at $453.32 \mathrm{~nm}$ and $521.04 \mathrm{~nm}$ wavelengths to estimate Ti excitation temperature distribution using two-line method. A high-speed video camera was used to capture 2-D image at the specified wavelength. The frame rate of the high-speed video camera was set to 3000 frames per second (fps). We confirmed that the measured highspeed video images had good reproducibility at each timing in the present experimental condition. Consequently, the accumulation and averaging were done four times for four cycles $\left(=4 t_{\text {valve }}^{\text {cyc }}\right)$ to reduce the contribution from a noise signal.

\subsection{Estimation of Ti excitation temperature}

The Ti excitation temperature $\left(T_{\mathrm{ex}}^{\mathrm{Ti}}\right)$ was ascertained from 2-D radiation intensity of Ti I at $453.32 \mathrm{~nm}$ and that of $\mathrm{Ti} \mathrm{I}$ at $521.04 \mathrm{~nm}$. Here, the radiation intensity $I_{453}$ of Ti I spectral line at $453.32 \mathrm{~nm}$ is superimposed from the contribution of two Ti I spectral lines at $453.3240 \mathrm{~nm}$ and at $453.4776 \mathrm{~nm}$, whereas the radiation intensity $I_{521}$ is obtained from a Ti I spectral line at $521.04 \mathrm{~nm}$. Consequently, the intensity ratio $I_{453} / I_{521}$ can be calculated as a function of $T_{\mathrm{ex}}^{\mathrm{Ti}}$ when the population of the excited states 
follows the Boltzmann distribution at the excitation temperature $T_{\mathrm{ex}}^{\mathrm{Ti}}$ :

$$
\frac{I_{453}}{I_{521}}=\frac{\frac{g_{p} A_{p q}}{\lambda_{p q}} \exp \left(-\frac{E_{p}}{k T_{\mathrm{ex}}^{\mathrm{Ti}}}\right)+\frac{g_{k} A_{k l}}{\lambda_{k l}} \exp \left(-\frac{E_{k}}{k T_{\mathrm{ex}}^{\mathrm{Ti}}}\right)}{\frac{g_{m} A_{m n}}{\lambda_{m n}} \exp \left(-\frac{E_{m}}{k T_{\mathrm{ex}}^{\mathrm{Ti}}}\right)}
$$

where $k$ is Boltzmann's constant, $\lambda_{p q}, \lambda_{k l}$ and $\lambda_{m n}$ are wavelengths for Ti I at 453.3240 $\mathrm{nm}$, at $453.4776 \mathrm{~nm}$ and at $521.0384 \mathrm{~nm}, g_{p}, g_{k}$ and $g_{m}$ are the degeneracy values of the upper level for respective spectral lines, $A_{p q}, A_{k l}$ and $A_{m n}$ are the transition probabilities for respective spectral lines, $E_{p}, E_{k}$ and $E_{m}$ is the upper state energy levels for respective spectral lines. These atomic constants, which were referred from the NIST database [35], are presented in table 3. As well known, the collision frequencies between the electron and heavy particles and between heavy particles are extremely high (e.g. $\sim 10^{16} \mathrm{~s}^{-1}$ at 300 torr) in thermal plasmas because the electron and gas temperatures are high as several thousands kelvin and the pressure is high as 300 torr. These high collision frequencies lead the plasma to near thermodynamic equilibrium condition. Thus, the population of the excited states follows the Boltzmann distribution in many case for thermal plasmas [34]. From this reason, it was assumed at present that the population of the excited states follows the Boltzmann distribution.

Figure 5 shows a curve of $I_{453} / I_{521}$ as a function of $T_{\mathrm{ex}}^{\mathrm{Ti}}$. Using this curve of $I_{453} / I_{521}-T_{\mathrm{ex}}^{\mathrm{Ti}}$, one can estimate $T_{\mathrm{ex}}^{\mathrm{Ti}}$ from measurements of $I_{453} / I_{521}$ for intensity ratio of the Ti I spectral lines. For this temperature estimation, the influence of continuum spectra was found to be negligible because the radiation intensity of continuum spectra around $521.04 \mathrm{~nm}$ and $453.32 \mathrm{~nm}$ wavelengths were very weak compared with those of these Ti I spectra lines. This neglect of the continuum was confirmed from another spectroscopic observation using a spectroscopic observation. In determination of the excitation temperature, for simplicity, Abel inversion was not performed. Strictly speaking, Abel inversion for the measured radiation intensities should be done to obtain the net radiation intensity distributions if the axis-symmetric structure can hold in the radiation intensity. However, the complete axis-symmetric structure cannot be obtained in the measured radiation intensity, and the incomplete axis-symmetric structure would involve an error in the estimation of temperature. On the other hand, the apparent radiation intensities integrated along the line of sight were used here to determine the excitation temperature with an error tolerance. The excitation temperature determined here is thus not completely local one but an indicator of the excitation temperature. Nevertheless, the excitation temperature determined here is roughly close to the real excitation temperature, and useful to estimate relative distribution of the excitation temperature. Consequently, the excitation temperature ascertained in this study would be overestimated or underestimated with error of $\pm 1000 \mathrm{~K}$ from our detailed temperature evaluation considering the radial temperature distribution. The error in temperature determination between with and without Abel inversion will be discussed in section 5.2. 


\section{Two-dimensional spectroscopic observation results}

\subsection{Spatial and temporal variation of Ti I radiation intensities}

Figure 6 portrays 2-D OES results for two Ti atomic lines. Panel (a) shows the solenoid valve open-close signal, panel (b) depicts a schematic of the estimated timing of feedstock injection into the ICTP torch, and panel (c) is the 2-D distribution of Ti I radiation intensity at $453.32 \mathrm{~nm}$ wavelength, and panel (d) portrays the 2-D distribution of Ti I radiation intensity at $521.04 \mathrm{~nm}$ wavelength. Panel (a) presents that the solenoid valve receives the open signal (high-level signal) at $t=0 \mathrm{~ms}$, and the close signal (lowlevel signal) at $t=8 \mathrm{~ms}$, where $t$ is the time. As portrayed in panel (b), we have already confirmed in another experiment that it takes approximately 6-8 $\mathrm{ms}$ for the solenoid valve to open and for Ti feedstock to travel from the inlet of the solenoid valve to the ICTP torch. After the feedstock reaches the torch at around $t=8-9 \mathrm{~ms}$, and the feeding rate becomes the value in the steady state at $t=9-16 \mathrm{~ms}$. After steady state feeding, the feeding rate decreases a stops at around $t=15-17 \mathrm{~ms}$. In panels (c) and (d), the coil end position is presented with axial coordinate $z$ and radial coordinate $r$. The radial position $r=0 \mathrm{~mm}$ in panels (c) and (d) almost corresponds to the central axis of the ICTP torch.

In panel (c), the radiation intensity of Ti I at $453.32 \mathrm{~nm}$ was extremely low at $t=0$ $6 \mathrm{~ms}$ because the Ti feedstock did not yet reach into the ICTP torch. At $t=6-8 \mathrm{~ms}$, the Ti I radiation intensity increased sharply. This sharp increase in the radiation intensity indicates that $\mathrm{Ti}$ feedstock reaches the torch. It began to be evaporated rapidly at around $t=6 \mathrm{~ms}$. It is noteworthy that, around $t=6 \mathrm{~ms}$, the Ti I radiation intensity was detected only around the on-axis region $(r=0 \mathrm{~mm})$, although it was then expanded from the on-axis region to the off-axis region at $t=8 \mathrm{~ms}$. This expansion suggests that the feedstock evaporation initially occurs around on-axis region. Then the evaporated Ti atoms might be diffused in the radial direction because of the high radial gradient of $\mathrm{Ti}$ density. At $t=8-20 \mathrm{~ms}$, the Ti I radiation intensity is kept high and static at the axial position of $z=15-40 \mathrm{~mm}$ and radial position of $|r|<10 \mathrm{~mm}$ below the coil-end region in the ICTP torch. This high and static radiation intensity distribution implies that the feedstock injection and its evaporation are almost in a steady state in the ICTP torch. After $t=20-22 \mathrm{~ms}$, the Ti I radiation intensity decreased with time. Then it became too low to be detected. This result reflects that feedstock feeding is well controlled to be stopped by the solenoid valve. Similar spatiotemporal behaviour of Ti I radiation intensity was found for the spectral line at $521.04 \mathrm{~nm}$ wavelength, as shown in panel (d). Consequently, spatiotemporal distributions of the radiation intensities from two $\mathrm{Ti}$ atomic lines were observed using the 2-D OES system.

\subsection{Spatiotemporal distribution of the Ti excitation temperature}

4.2.1. Estimation of $2 D$ Ti excitation temperature The excitation temperature $T_{\mathrm{ex}}^{\mathrm{Ti}}$ was estimated from the radiation intensities of the two Ti I lines. Figure 7 depicts (a) the 
radiation intensity distribution of $\mathrm{Ti} \mathrm{I}$ at $\lambda=453.32 \mathrm{~nm}$, (b) that at $\lambda=521.04 \mathrm{~nm}$, and (c) $T_{\mathrm{ex}}^{\mathrm{Ti}}$ estimated from the above two intensity distributions at $t=16 \mathrm{~ms}$. In panel (c), the region painted in black corresponds to the region in which $T_{\mathrm{ex}}^{\mathrm{Ti}}$ was unable to be estimated because of its low radiation intensity. In addition, the region in which $T_{\mathrm{ex}}^{\mathrm{Ti}}$ was estimated as below $2500 \mathrm{~K}$ is also painted in black because of a lack of accuracy in determination of $T_{\mathrm{ex}}^{\mathrm{Ti}}$.

In this figure, $T_{\mathrm{ex}}^{\mathrm{Ti}}$ on the axis around $|r|<10 \mathrm{~mm}$ was estimated as about 2500$4000 \mathrm{~K}$, which is lower than the off-axis temperature. This low temperature might arise from a quenching effect of low-temperature Ar carrier gas (approx. $300 \mathrm{~K}$ ) injected together with Ti feedstock into the ICTP torch [31]. Furthermore, evaporation of the Ti feedstock consumes energy around the on-axis, which can decrease the temperature. On the other hand, $T_{\mathrm{ex}}^{\mathrm{Ti}}$ around $|r|=10-15 \mathrm{~mm}$, which is the off-axis temperature, was estimated as higher than $4500 \mathrm{~K}$. This high temperature at the off-axis might be attributable to induction heating by the eddy current in the ICTP. The injected Ti feedstock is evaporated, resulting in high-density Ti atoms. Mixing of Ti atoms to Ar- $\mathrm{O}_{2}$ plasma increases the electrical conductivity markedly around 4500-6000 K [31] because of lower ionization potential of $\mathrm{Ti}$ than Ar or O atoms. Consequently, at the off-axis region, the current density from inductive coupling can be elevated by increased electrical conductivity, involving an increase in the on-axis temperature. Such 2D temperature estimation can be done using 2D-OES measurements.

\subsubsection{Relation between estimated $T_{\mathrm{ex}}^{\mathrm{Ti}}$ and the radiation intensities of $\mathrm{Ti}$ and $\mathrm{TiO}$} It is useful to investigate the relation between the estimated $T_{\mathrm{ex}}^{\mathrm{Ti}}$ and the radiation intensities of $\mathrm{Ti}$ and $\mathrm{TiO}$. Figure 8 presents a comparison of spatial distributions among (a) the radiation intensity of $\mathrm{Ti}$ atomic line at $453.32 \mathrm{~nm}$, (b) estimated $T_{\mathrm{ex}}^{\mathrm{Ti}}$, and (c) the radiation intensity of $\mathrm{TiO}$. These are obtained at $t=16 \mathrm{~ms}$ after initiation of the open signal for the solenoid valve, as described in the previous section. The TiO molecular radiation intensity distribution was referred from our earlier work [31]. From the radiation intensity distributions of $\mathrm{Ti}$ and $\mathrm{TiO}$ shown in panels (a) and (c), we were able to infer the density distribution of $\mathrm{Ti}$ and $\mathrm{TiO}$, while also considering the temperature in panel (b).

As shown in panel (a), the Ti atoms have high density around the axis just below the coil end, where $T_{\mathrm{ex}}^{\mathrm{Ti}}$ was estimated as $2500-4000 \mathrm{~K}$ around the axis in panel (b), as described in the previous section. Panel (c) depicts that the $\mathrm{TiO}$ radiation intensity is high only around on-axis region. This strong $\mathrm{TiO}$ radiation intensity distribution on the axis closely corresponds to low- $T_{\mathrm{ex}}^{\mathrm{Ti}}$ region around on-axis shown in panel (b). In addition, the $\mathrm{TiO}$ radiation intensity became highest downstream of the torch. This downstream region approximates the region in which $T_{\mathrm{ex}}^{\mathrm{Ti}}$ was estimated below $2500 \mathrm{~K}$. This agreement suggests that $\mathrm{TiO}$ molecules are formed this downstream region because of association reactions $\mathrm{Ti}+\mathrm{O}+\mathrm{M} \rightarrow \mathrm{TiO}+\mathrm{M}$ at low temperature, where $\mathrm{M}$ is the third particle. 
4.2.3. Spatiotemporal distribution of Ti excitation temperature For one cycle of the valve open to close, the $T_{\mathrm{ex}}^{\mathrm{Ti}}$ was estimated. Its spatiotemporal distribution was compared with the radiation intensity distribution of $\mathrm{Ti}$ and $\mathrm{TiO}$. Figure 9 shows the spatiotemporal distributions of (a) the Ti I radiation intensity, (b) the estimated $T_{\mathrm{ex}}^{\mathrm{Ti}}$, and $(\mathrm{c})$ the $\mathrm{TiO}$ radiation intensity in one cycle of the solenoid valve for intermittent feeding.

As panel (b) shows, $T_{\mathrm{ex}}^{\mathrm{Ti}}$ was not estimated between $t=0-4 \mathrm{~ms}$ because the $\mathrm{Ti}$ radiation intensity was extremely low in the ICTP torch. At $t=6-8 \mathrm{~ms}, T_{\mathrm{ex}}^{\mathrm{Ti}}$ was estimated as $2500-4000 \mathrm{~K}$ around on the axis, as $4500-8000 \mathrm{~K}$ in off-axis region in the ICTP torch. At $t=8-18 \mathrm{~ms}, T_{\mathrm{ex}}^{\mathrm{Ti}}$ distribution is almost static, except at a downstream portion. That downstream portion has a decreased temperature region around $z=40-50$ $\mathrm{mm}$ and $|r|=10 \mathrm{~mm}$. The radiation intensity of TiO becomes strong, as shown in panel (c) especially at $t=14-16 \mathrm{~ms}$. This fact suggests that $\mathrm{TiO}$ molecules are formed at this downstream region through an association reaction by decreased temperature. From $t=16 \mathrm{~ms}$, injection amount of feedstock was gradually reduced by closing the valve, as described previously. This suppression of feedstock injection might engender recovery in the temperature, especially from upstream of the ICTP torch. Consequently, $T_{\mathrm{ex}}^{\mathrm{Ti}}$ was found to be recovered gradually after $t=16 \mathrm{~ms}$, as shown in panel (b). In panel (c), the TiO radiation intensity was detected strongly at $t=8-18 \mathrm{~ms}$. This intensity was detected as high only around the on-axis region during $t=8-18 \mathrm{~ms}$. After $t=18 \mathrm{~ms}$, the $\mathrm{TiO}$ radiation intensity decreased rapidly because $\mathrm{TiO}$ molecules might mainly be transported by axial convection and because $\mathrm{TiO}$ can be dissociated to produce $\mathrm{Ti}+\mathrm{O}$ by recovering temperature.

\section{Discussion}

\subsection{Equilibrium particle composition for the Ar-O-Ti system}

The equilibrium particle composition for the Ar-O-Ti system was calculated to investigate behaviour of $\mathrm{Ti}$ atoms, and $\mathrm{TiO}$ and $\mathrm{TiO}_{2}$ molecules as a function of temperature. The minimization of Gibbs's free energy of a system of Ar-O-Ti was performed to calculate the equilibrium particle compositions. These calculations were conducted under constant pressure of 300 Torr (approx. $40 \mathrm{kPa}$ ). In this calculation, species only in the gas phase were considered. intentionally because we consider precursor molecule formation at first. The calculation procedure is the same as that used in our earlier work [31]. The equilibrium particle compositions were calculated for two gas mixture conditions: $89 \mathrm{~mol} \% \mathrm{Ar}-10 \mathrm{~mol} \% \mathrm{O}_{2}-1 \mathrm{~mol} \% \mathrm{Ti}$ and $50 \mathrm{~mol} \% \mathrm{Ar}-25$ $\mathrm{mol} \% \mathrm{O}_{2}-25 \mathrm{~mol} \% \mathrm{Ti}$. Both these conditions have more than 2.0 in molar ratio of oxygen atom to titanium atom, and thus all $\mathrm{Ti}$ atoms can react with oxygen atoms to produce $\mathrm{TiO}_{2}$ molecules through reactions of $\mathrm{Ti}(\mathrm{g})+\mathrm{O}_{2} \rightarrow \mathrm{TiO}_{2}(\mathrm{~g})$. The second condition of $50 \% \mathrm{Ar}-25 \% \mathrm{O}_{2}-25 \% \mathrm{Ti}$ mixture has a much higher $\mathrm{Ti}$ inclusion ratio. Therefore, high density $\mathrm{TiO}$ and $\mathrm{TiO}_{2}$ vapour can be formed compared to the first condition of 
$89 \% \mathrm{Ar}-10 \% \mathrm{O}_{2}-1 \%$ Ti mixture. Figures 10 (a) and (b) present the calculated equilibrium compositions of $89 \% \mathrm{Ar}-10 \% \mathrm{O}_{2}-1 \% \mathrm{Ti}$ and $50 \% \mathrm{Ar}-25 \% \mathrm{O}_{2}-25 \% \mathrm{Ti}$ mixtures at a pressure of 300 torr ( $\sim 40 \mathrm{kPa}$ ). In panel (a) for $89 \% \mathrm{Ar}-10 \% \mathrm{O}_{2}-1 \% \mathrm{Ti}$ mixture, particles of all kinds are ionized at temperatures higher than $10000 \mathrm{~K}$. At temperatures of 10000 - $5000 \mathrm{~K}$, Ar and $\mathrm{O}$ atoms are the predominant species. At 5000-3000 K, TiO(g) is formed by the association reaction of $\mathrm{Ti}(\mathrm{g})+\mathrm{O} \rightarrow \mathrm{TiO}(\mathrm{g})$. Then $\mathrm{TiO}(\mathrm{g})$ becomes a dominant species. At temperatures below $3000 \mathrm{~K}, \mathrm{TiO}_{2}(\mathrm{~g})$ in gas phase is also formed markedly by the association reaction of $\mathrm{TiO}(\mathrm{g})+\mathrm{O} \rightarrow \mathrm{TiO}_{2}(\mathrm{~g})$. In addition, the $\mathrm{TiO}_{2}$ molecule becomes the dominant species among $\mathrm{Ti}$ species at temperatures lower than $3500 \mathrm{~K}$. Panel (b) for 50\% Ar- $25 \% \mathrm{O}_{2}-25 \%$ Ti mixture shows a similar composition variation as a function of temperature to the $89 \% \mathrm{Ar}-10 \% \mathrm{O}_{2}-1 \% \mathrm{Ti}$ mixture. However, the partial pressure of $\mathrm{TiO}_{2}(\mathrm{~g})$ monomer becomes much higher for the $50 \% \mathrm{Ar}-25 \% \mathrm{O}_{2^{-}}$ $25 \% \mathrm{Ti}$ mixture than for $89 \% \mathrm{Ar}-10 \% \mathrm{O}_{2}-1 \% \mathrm{Ti}$ at temperatures below $4000 \mathrm{~K}$. If such a high partial pressure of $\mathrm{TiO}_{2}(\mathrm{~g})$ can be realized, then it may lead to $\mathrm{TiO}_{2}(\mathrm{~s}, \ell)$ nucleation possible in the ICTP torch. On the other hand, $\mathrm{O}_{2}$ partial pressure becomes lower because $\mathrm{O}$ atoms are consumed through formation of $\mathrm{TiO}_{2}(\mathrm{~g})$ and $\mathrm{TiO}(\mathrm{g})$.

In our previous section, we discussed the relationship between the Ti excitation temperature, $\mathrm{Ti}$ and $\mathrm{TiO}$ radiation intensities. Results from figures 8 and 9 indicated that $\mathrm{TiO}(\mathrm{g})$ was effectively formed in a region at temperatures below $5000 \mathrm{~K}$. These results fairly agree with the density increase of $\mathrm{TiO}(\mathrm{g})$ with decreasing temperature from $5000 \mathrm{~K}$ in the equilibrium compositions.

\subsection{Temperature difference between with and without Abel inversion}

Abel inversion technique for obtained radiation intensities was partially used to check a influence in temperature determination between with and without Abel inversion. The Abel inversion was made for the two Ti radiation intensities measured at an axial position of $z=20 \mathrm{~mm}$ in figures $7(\mathrm{a})$ and $7(\mathrm{~b})$. Generally, the Abel inversion technique assumes an axis-symmetric structure for the radiation intensity and requires to assign the center axis. However, the radiation intensity distribution from the plasma is not completely axis-symmetric structure. The assignment of the center axis position is therefore one parameter to produce an error in temperature determination.

Figure 11 shows the estimation results on the radial distribution of $T_{\mathrm{ex}}^{\mathrm{Ti}}$ with Abel

inversion and without Abel inversion. This figure includes three results on $T_{\mathrm{ex}}^{\mathrm{Ti}}$ for three different central axis positions with Abel inversion: $r=0,1$, and $2 \mathrm{~mm}$ in figures 7 (a) and $7(\mathrm{~b})$. In figure 11, the solid black curve shows the estimation result on $T_{\mathrm{ex}}^{\mathrm{Ti}}$ without Abel inversion for the specified center axis position of $r=1 \mathrm{~mm}$. The dashed curves indicate the estimation results on $T_{\mathrm{ex}}^{\mathrm{Ti}}$ with Abel inversion for the three different center axis positions $r=0,1,2 \mathrm{~mm}$. The horizontal axis in this figure corresponds to the radial position $r^{\prime}$ from the specified center axis. As seen in figure 11, $T_{\mathrm{ex}}^{\mathrm{Ti}}$ around the central axis $r^{\prime}<3 \mathrm{~mm}$ were estimated to be about 3000-3500 K with Abel inversion for different center axis positions, whilst $T_{\mathrm{ex}}^{\mathrm{Ti}}$ was evaluated as about $3700 \mathrm{~K}$ without 
Abel inversion. At $0 \mathrm{~mm}<r^{\prime}<7 \mathrm{~mm}$, the temperature differences among these four curves are thus less than $1000 \mathrm{~K}$. On the other hand, at radial positions $r^{\prime}>7 \mathrm{~mm}$, there are large temperature differences among three dashed curves. As seen, Abel inversion with uncertain central axis position produces a serious error $>2000 \mathrm{~K}$ in temperature determination. From the above error estimation, it was found that the temperature error without Abel inversion around the center axis is less than $1000 \mathrm{~K}$. In addition, even with Abel inversion, uncertain center axis position for incomplete axis-symmetric structure provides an error in temperature determination about 2000 $\mathrm{K}$ at $r^{\prime}>7 \mathrm{~mm}$ in figures 7(c) and 8(b). Thus, Abel inversion was not carried out for two-dimensional temperature determination in the present paper. Further accurate 2-D temperature determination needs a computer tomographic technique with different observation directions in future work. Nevertheless, the 2-D temperature estimation result presented here offers important information on distribution and its time variation during nanoparticle synthesis.

\subsection{Possibility in nucleation occurrence in the torch}

In this section, just a possibility in nucleation occurrence in the torch is discussed on the basis of saturation vapor pressure and then supersaturation condition. This discussion does not explain complete routes to $\mathrm{TiO}_{2} \mathrm{NP}$ formation, but only a nucleation possibility in the torch. As shown in figure 10, there are three Ti-containing species, i.e. Ti atom, $\mathrm{TiO}(\mathrm{g})$ and $\mathrm{TiO}_{2}(\mathrm{~g})$ molecules, in $\mathrm{Ar}-\mathrm{O}_{2}-\mathrm{Ti}$ system at temperatures below $3000 \mathrm{~K}$. Molecules $\mathrm{TiO}_{2}(\mathrm{~g})$ plays an important role directly for $\mathrm{TiO}_{2}$ nucleation. In addition, $\mathrm{TiO}(\mathrm{g})$ molecule may also have an important role for $\mathrm{TiO}$ nucleation (e.g., $\alpha$ - $\mathrm{TiO}(\mathrm{s}), \beta$ $\mathrm{TiO}(\mathrm{s}))$ and then it oxides to produce $\mathrm{TiO}_{x}(\mathrm{~s})(1<x<2)$ clusters. However, there are lacks of sufficient physical data about $\mathrm{TiO}(\mathrm{s})$ because it is unstable compared to $\mathrm{TiO}_{2}(\mathrm{~s})$. Thus, we here focused only on a possibility in nucleation occurrence for $\mathrm{TiO}_{2}(\mathrm{~s})$ from $\mathrm{TiO}_{2}(\mathrm{~g})$ in the torch. If we consider other routes to $\mathrm{TiO}_{2}(\mathrm{~s})$ nucleation, the nucleation occurrence possibility in the torch would be further higher.

From the temperature distribution determined in the ICTP torch, we can estimate the $2 \mathrm{D}$ distribution of saturation vapor pressure of $\mathrm{TiO}_{2}(\mathrm{~g})$. The saturation vapour pressure distribution in the torch is an important parameter to guess nucleation occurrence in the ICTP torch during $\mathrm{TiO}_{2}$ nanopowder synthesis. The saturation vapour pressure was calculated from Clausius-Clapeyron equation $\left(S_{\text {clau }}\right)$ :

$$
P_{\text {sat }}^{\mathrm{TiO}_{2}}=P_{0} \exp \left\{\frac{(\Delta H)_{\mathrm{vap}}}{R}\left(\frac{1}{T_{0}}-\frac{1}{T}\right)\right\}
$$

where $P_{\mathrm{sat}}^{\mathrm{TiO}_{2}}$ is the saturation vapour pressure of $\mathrm{TiO}_{2}, P_{0}$ is the reference pressure (atmospheric pressure), $(\Delta H)_{\text {vap }}$ stands for the latent heat for vaporization of $\mathrm{TiO}_{2}, R$ is the gas constant, $T_{0}$ signifies the vaporization temperature of $\mathrm{TiO}_{2}$ at atmospheric pressure, and $T$ is the gas temperature. In this estimation of the saturation vapor pressure distribution, $T_{\mathrm{ex}}^{\mathrm{Ti}}$ was used as gas temperature $T$ on the assumption of LTE condition. The physical constants and quantities of monomer were collected from 
databooks [36, 37].

Figure 12 shows the estimated saturation vapour pressure distribution of $\mathrm{TiO}_{2}$ in the ICTP torch. Panel(a) shows the configuration of the ICTP torch and the estimation region, while panel (b) is the estimated saturation vapour pressure of $\mathrm{TiO}_{2}$ gas $\left(P_{\mathrm{sat}}^{\mathrm{TiO}_{2}}\right)$.

As seen in panel(b), $P_{\text {sat }}^{\mathrm{TiO}_{2}}$ is calculated to be $10^{7}-10^{8} \mathrm{~Pa}$ at off-axis region, whereas it is less than $10^{5} \mathrm{~Pa}$ at on-axis region. According to homogeneous nucleation theory, nucleation can occur when the saturation ratio $S$ is greater than unity (supersaturation) at least. The saturation ratio $S$ is expressed as following equation:

$$
S=\frac{P^{\mathrm{TiO}_{2}}}{P_{\mathrm{sat}}^{\mathrm{TiO}}}
$$

where $P_{\mathrm{TiO}_{2}}$ is the partial pressure of $\mathrm{TiO}_{2}(\mathrm{~g})$. As shown in panel(b), the saturation vapour pressure is greater than the ambient pressure $\left(300\right.$ torr $\left.\sim 4 \times 10^{4} \mathrm{~Pa}\right)$ in most of vapour region. This means that nucleation cannot occur there. However, at downstream of on-axis region in the ICTP torch, the saturation vapour pressure $P_{\mathrm{sat}}^{\mathrm{TiO}_{2}}$ becomes lower than ambient pressure. This implies that $\mathrm{TiO}_{2}$ vapour can be in supersaturation state if Ti feedstock is efficiently evaporated and then fully mixed with oxygen as shown in figure 10(b). This result infers that $\mathrm{TiO}_{2}$ nuclei could be generated in this downstream region in the ICTP torch. However, it should be noted that nucleation occurrence could be estimated if the partial pressure of $\mathrm{TiO}_{2}(\mathrm{~g})$ would be measured in the ICTP torch. The evaluation of the partial pressure of $\mathrm{TiO}_{2}(\mathrm{~g})$ and then nucleation occurrence are underway in our group.

\section{Conclusions}

Two-dimensional optical emission spectroscopic (2-D OES) observations were conducted to investigate the spatiotemporal distribution of radiation intensities from $\mathrm{Ti}$ atomic lines and $\mathrm{TiO}$ molecular spectra during $\mathrm{TiO}_{2}$ nanopowder synthesis using an ICTP torch. Furthermore, the 2-D distribution of Ti excitation temperature was estimated from the 2-D OES results in the ICTP torch. The 2-D OES radiation intensities of $\mathrm{Ti}$ and $\mathrm{TiO}$, and the 2-D Ti excitation temperature elucidated a fundamental relation between the $\mathrm{Ti}$ and $\mathrm{TiO}$ vapour and the temperature distribution. These results will be useful to discuss the nucleation occurrence of nanoparticles in the plasma torch.

\section{Acknowledgments}

This study was supported in part by a Grant-in-Aid for Scientific Research (KAKENHI) (A) (26249034), The Japan Society for the Promotion of Science (JSPS), Japan, and by a JSPS KAKENHI Grant Number JP15J02707. 


\section{References}

[1] Malato S, Blanco J, Alarcon D C, Maldonado M I, Fernandez-Ibanez P and Gernjak W 2007 Photocatalytic decontamination and disinfection of water with solar collectors. Catalysis Today 122 137-49

[2] Li J, Zhao X, Wei H, Gu Z Z, and Lu Z 2008 Macroporous ordered titanium dioxide $\left(\mathrm{TiO}_{2}\right)$ inverse opal as a new label-free immunosensor. Analytica Chemica Acta 625 63-9

[3] Gratzel M 2001 Photoelectrochemical cells. Nature 414 338-44

[4] Biju K P and Jain M K 2008 Effect of crystallization on humidity sensing properties of sol-gel derived nanocrystalline $\mathrm{TiO}_{2}$ thin films. Thin Solid Films 516 2175-80

[5] Tsai Y C, Hsi C H, Bai H, Fan S K and Sun D H 2012 Single-step synthesis of Al-doped TiO 2 nanoparticles using non-transferred thermal plasma torch. Jpn. J. Appl. Phys. 51 01AL01

[6] Shon K H, Cho L D, Na H S, Kim B J, Park J H and Kim H J 2009 Development of a novel method to prepare Fe- and $\mathrm{Al}$-doped $\mathrm{TiO}_{2}$ from wastewater. J. Ind. Eng. Chem. 15 476-82

[7] Barolo G, Livraghi S, Chiesa M, Cristina M, Paganini C and Giamello E 2012 Mechanism of the photoactivity under visible light of $\mathrm{N}$-doped titanium dioxide. charge carries migration in irradiated $\mathrm{N}_{-} \mathrm{TiO}_{2}$ investigated by electron paramagnetic resonance. J. Phys. Chem. C 116 20887-94

[8] Lee K N, Kim Y, Lee C W and Jai-Sung Lee J S 2011 Simultaneous amination of TiO 2 nanoparticles in the gas phase synthesis for bio-medical applications Mater. Sci. Eng. 18082021

[9] Mio M, Kogoma M, Fukui H, and Kogoma A 2010 Control of inflammation using adsorption of inflammatory by nano-particles Chem. Eng. 55 603-8

[10] Shigeta M and Murphy A B 2011 Thermal plasmas for nanofabrication. J. Phys. D: Appl. Phys. 44174025

[11] Girshick S L, Chiu C P, Muno R, Wu C Y, Yang L, Singh S K, and McMurry P H 1993 Thermal plasma synthesis of ultrafine iron particles. J. Aerosol Sci. 24 367-82

[12] Shigeta M, Watanabe T, and Nishiyama H 2004 Numerical investigation for nano-particle synthesis in an RF inductively coupled plasma. Thin Solid Films 457 192-200

[13] Oh S M and Ishigaki T 2004 Preparation of pure rutile and anatase $\mathrm{TiO}_{2}$ nanopowders using RF thermal plasma. Thin Solid Films 457 186-91

[14] Lee J E, Oh S M, and Park D W 2004 Synthesis of nano-sized Al doped $\mathrm{TiO}_{2}$ powders using thermal plasma. Thin Solid Films 457 230-4

[15] Ishigaki T, Oh S M, Li J G, and Park D W 2005 Controlling the synthesis of TaC nanopowders by injecting liquid precursor into RF induction plasma. Sci. \& Technol. Advanced Mater. 6 111-8

[16] Tong L and Reddy R G 2006 Thermal plasma synthesis of SiC nano-powders/nano-fibers. Materials Research Bulletin 41 2303-10

[17] Ishigaki T and Li J G 2007 Synthesis of functional nanocrystallites through reactive thermal plasma processing. Sci. ES Technol. Advanced Mater. 8 617-23

[18] Li J G, Ikeda M, Ye R, Moriyoshi Y, and Ishigaki T 2007 Control of particle size and phase formation of $\mathrm{TiO}_{2}$ nanoparticles synthesized in RF induction plasma. J. Phys. D: Appl. Phys. $402348-53$

[19] Tanaka Y, Nagumo T, Sakai H, Uesugi Y, and Nakamura K 2010 Nanoparticle synthesis using high-powered pulse-modulated induction thermal plasma. J. Phys. D: Appl. Phys. 43265201

[20] Tanaka Y, Sakai H, Tsuke T, Uesugi Y, Sakai Y, and Nakamura K 2011 Influence of coil current modulation on $\mathrm{TiO}_{2}$ nanoparticle synthesis using pulse-modulated induction thermal plasmas. Thin Solid Films $\mathbf{5 1 9}$ 7100-05

[21] Tanaka Y, Tsuke T, Guo W, Uesugi Y, Ishijima T, Watanabe S, and Nakamura K 2012 A large amount synthesis of nanopowder using modulated induction thermal plasmas synchronized with intermittent feeding of raw materials. J. Phys. D: Conf. Ser. 406012001

[22] Tanaka Y, Sakai H, Tsuke T, Guo W, Uesugi Y, Sakai Y and Nakamura K 2011 Nanoparticle synthesis using high-power modulated induction thermal plasmas with intermittent synchronized 
feeding of raw materials. Proc. 20th Int. Symp. Plasma Chem. ISPC-20, 346, Philadelphia, USA

[23] Tanaka Y and Sakuta T 2003 Temperature control of Ar induction thermal plasma with diatomic molecular gases by pulse-amplitude modulation of coil current. Plasma Sources Sci. \&3 Technol. $1269-77$

[24] Tanaka Y, Uesugi Y, and Sakuta T 2007 Controlling the number of excited atoms flowing into the reaction chamber using pulse-modulated induction thermal plasmas at atmospheric pressure. Plasma Sources Sci. \& Technol. 16 281-9

[25] Tanaka Y, Guo W, Kodama N, Uesugi Y, Ishijima T, Watanabe S and Nakamura K 2013 A novel approach for large amount synthesis of $\mathrm{TiO}_{2}$ nanopowder using modulated induction thermal plasmas with time-controlled feeding of feedstock. Proc. 21st Int. Symp. Plasma Chem. ISPC-21, 52, Cairns, Australia

[26] Kodama N, Kita K, Tanaka Y, Uesugi Y, Ishijima T, Watanabe S, and Nakamura K 2014 A method for large-scale synthesis of Al-doped $\mathrm{TiO}_{2}$ nanopowder using pulse-modulated induction thermal plasmas with time-controlled feedstock feeding. J. Phys. D: Appl. Phys. 47195304

[27] Colombo V, Ghedini E, Gherardi M, and Sanibondi P 2013 Evaluation of precursor evapouration in Si nanoparticle synthesis by inductively coupled thermal plasmas. Plasma Sources Sci. Technol. 22035010

[28] Watanabe T, and Fujiwara K 2004 Nucleation and growth of oxide nanoparticles prepared by induction thermal plasmas Chem. Eng. Comm. 191 1343-61

[29] Shigeta M, and Watanabe T 2010 Growth model of binary alloy nanopowders for thermal plasma synthesis J. Appl. Phys. 108043306

[30] Kodama N, Kita K, Tanaka Y, Uesugi Y, Ishijima T, Watanabe S, and Nakamura K 2014 Twodimensional spectroscopic observation of a pulse-modulated induction thermal plasma torch for nanopowder synthesis. J. Phys.: Conf. Ser. 550012026

[31] Kodama N, Kita K, Ishisaka Y, Tanaka Y, Uesugi Y, Ishijima T, Sueyasu S, and Nakamura K 2016 Fundamental study of Ti feedstock evaporation and precursor formation process in inductively coupled thermal plasmas during $\mathrm{TiO}_{2}$ nanopowder synthesis. J. Phys. D: Appl. Phys. 49305501

[32] Olesik J W and Hieftje G M 1985 Optical imaging spectrometers Anal. Chem. 57 2049-55

[33] Webb M R and Hieftje G M Hieftje 2006 Improved monochromatic imaging spectrometer Appl. Spectro. $6057-60$

[34] Boulos M I, Fauchais P and Pfender E 1997 Thermal Plasmas Fundamentals and Applications vil $I$ (New York: Plenum)

[35] NIST Atomic Spectra Database, http://www.nist.gov/pml/data/asd.cfm

[36] Samsonov G V 1982 The oxide handbook second ed. (New York: IFI/Plenum)

[37] The Japan Institute of Metals 2007 Metals Data Book Fourth ed. (Tokyo: Maruzen) 
Table 1. Experimental conditions.

\begin{tabular}{|c|c|}
\hline Time-averaged input power & $20 \mathrm{~kW}$ \\
\hline Fundamental frequency of the coil current & $304 \mathrm{kHz}$ \\
\hline Modulation & Non-modulation \\
\hline Pressure & 300 Torr $(\sim 40 \mathrm{kPa})$ \\
\hline Gas composition & Ar: $90 \mathrm{~L} \mathrm{~min}^{-1}, \mathrm{O}_{2}: 10 \mathrm{~L} \mathrm{~min}^{-1}$ \\
\hline Carrier gas flow rate & Ar: $4 \mathrm{~L} \mathrm{~min}^{-1}$ \\
\hline Quenching gas & Non-injection \\
\hline Valve open-close cycle & $30 \mathrm{~ms}$ \\
\hline Valve open-close time & $8 / 22 \mathrm{~ms}\left(27 \% \mathrm{DF}_{\text {valve }}\right)$ \\
\hline Powder feed rate $g_{\text {pow }}$ & $4-7 \mathrm{~g} \mathrm{~min}^{-1}$ \\
\hline Feedstock & $\begin{array}{l}100 \mathrm{wt} \% \mathrm{Ti} \text { powder } \\
\bar{d}=27 \mu \mathrm{m}, d<45 \mu \mathrm{m}\end{array}$ \\
\hline
\end{tabular}


Table 2. Two-dimensional spectroscopic observation conditions.

\begin{tabular}{ll}
\hline Observation area & $47 \times 46 \mathrm{~mm}^{2}$ region below the coil end \\
\hline Diffraction grating & 1200 grooves $/ \mathrm{mm}$ \\
\hline Wavelength resolution & $0.4 \mathrm{~nm}$ \\
\hline Spectral lines observed & $\mathrm{Ti} \mathrm{I}(453.32 \mathrm{~nm})$ and Ti I $(521.04 \mathrm{~nm})$ \\
\hline $\begin{array}{l}\text { Frame rate for high speed } \\
\text { video camera }\end{array}$ & $3000 \mathrm{fps}$ \\
\hline
\end{tabular}


Table 3. Physical quantities for respective Ti I spectra.

\begin{tabular}{lllll}
\hline$\lambda[\mathrm{nm}]$ & Config. & $E[\mathrm{eV}]$ & $A\left[\times 10^{6} \mathrm{~s}^{-1}\right]$ & $g$ \\
\hline 453.3204 & $3 \mathrm{~d}^{3} 4 \mathrm{~s}-3 \mathrm{~d}^{3} 4 \mathrm{p}$ & 3.5827 & 88.3 & 11 \\
\hline 453.4776 & $3 \mathrm{~d}^{3} 4 \mathrm{~s}-3 \mathrm{~d}^{3} 4 \mathrm{p}$ & 3.5693 & 68.7 & 9 \\
\hline 521.0384 & $3 \mathrm{~d}^{2} 4 \mathrm{~s}^{2}-3 \mathrm{~d}^{2} 4 \mathrm{~s} 4 \mathrm{p}$ & 2.4269 & 3.89 & 9 \\
\hline
\end{tabular}




\section{Figure captions}

Figure 1. The principle of 2-D OES system.

Figure 2. Experimental apparatus using an ICTP torch and solenoid valve.

Figure 3. Overall view of the experimental apparatus used for nanopowder fabrication.

Figure 4. Two-dimensional spectroscopic observation region and observation system using an imaging spectrometer and high-speed video camera.

Figure 5. Relation between $I_{453} / I_{521}$ and the Ti excitation temperature.

Figure 6. 2-D OES results for two Ti atomic lines. (a) High-speed solenoid valve open-close signal. (b) Estimated actual feedstock injection timing into the ICTP torch. (c) Ti I radiation intensity at $453.32 \mathrm{~nm}$ wavelength. (d) Ti I radiation intensity at $521.04 \mathrm{~nm}$ wavelength.

Figure 7. Comparison between Ti I radiation intensities and estimated Ti excitation temperature distribution at $t=16 \mathrm{~ms}$. (a) Ti I radiation intensity at $453.32 \mathrm{~nm}$ wavelength. (b) Ti I radiation intensity at $521.04 \mathrm{~nm}$ wavelength. (c) 2-D distribution of $\mathrm{Ti}$ excitation temperature.

Figure 8. Comparison between $\mathrm{Ti} \mathrm{I}$ and $\mathrm{TiO}$ radiation intensities and estimated $\mathrm{Ti}$ excitation temperature distribution at $t=16 \mathrm{~ms}$. (a) Ti I radiation intensity at 453.32 $\mathrm{nm}$ wavelength. (b) 2-D distribution of $\mathrm{Ti}$ excitation temperature. (c) TiO radiation intensity obtained from our earlier work [31]. 
Figure 9. Comparison between 2-D OES results and estimated Ti excitation temperature distribution. (a) Ti I radiation intensity at $453.32 \mathrm{~nm}$ wavelength. (b) 2-D distribution of $\mathrm{Ti}$ excitation temperature. (c) $\mathrm{TiO}$ radiation intensity obtained from our earlier work [31].

Figure 10. Equilibrium particle compositions for the $\mathrm{Ar}-\mathrm{O}_{2}-\mathrm{Ti}$ system: (a) $89 \% \mathrm{Ar}-$ $10 \% \mathrm{O}_{2}-1 \% \mathrm{Ti}$, and (b) $50 \% \mathrm{Ar}-25 \% \mathrm{O}_{2}-25 \% \mathrm{Ti}$.

Figure 11. Estimation result of Ti excitation temperature with Abel inversion at $z=20 \mathrm{~mm}$.

Figure 12. Estimation result of $\mathrm{TiO}_{2}(\mathrm{~g})$ saturation vapour pressure in the ICTP torch. 


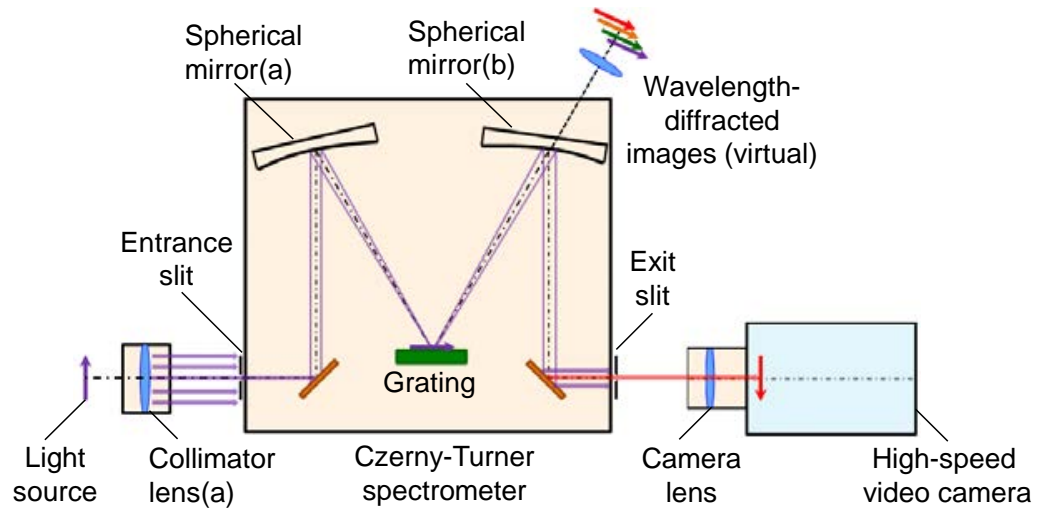

Figure 1. The principle of 2-D OES system. 


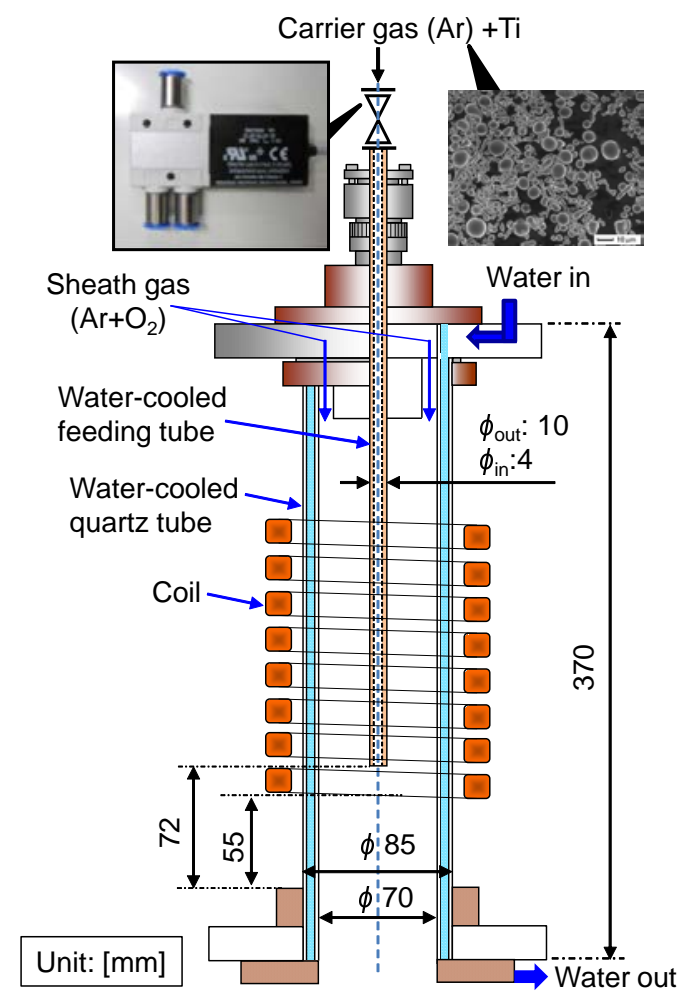

Figure 2. Experimental apparatus using an ICTP torch and solenoid valve. 


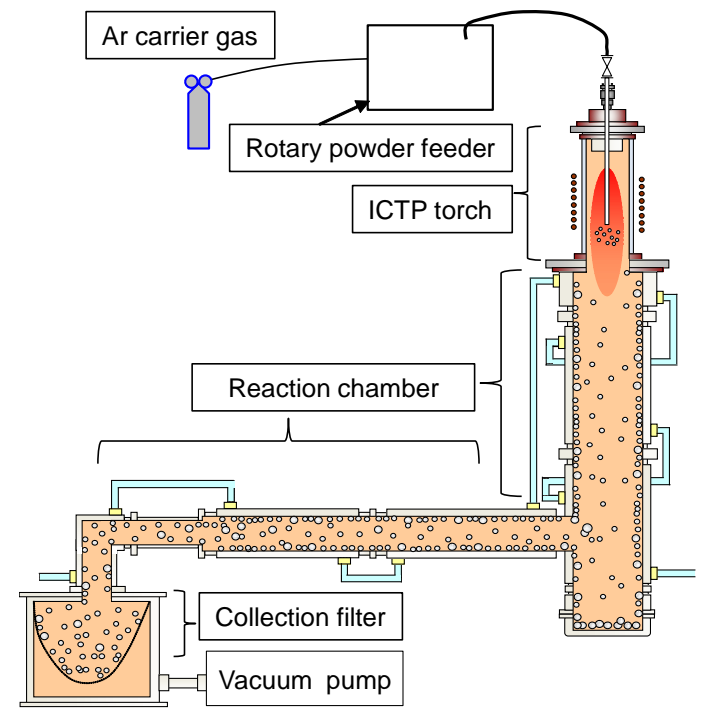

Figure 3. Overall view of the experimental apparatus used for nanopowder fabrication. 


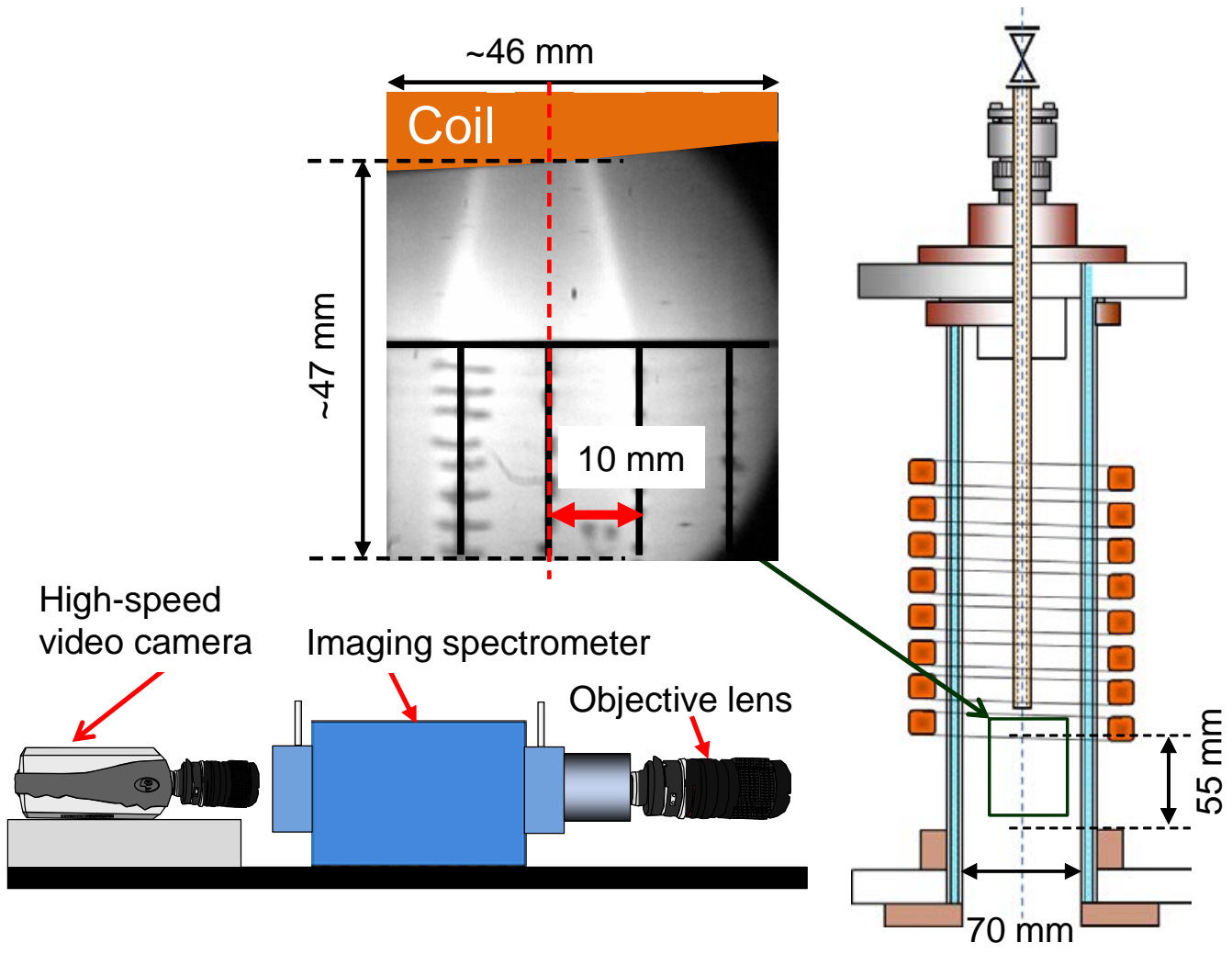

Figure 4. Two-dimensional spectroscopic observation region and observation system using an imaging spectrometer and high-speed video camera. 


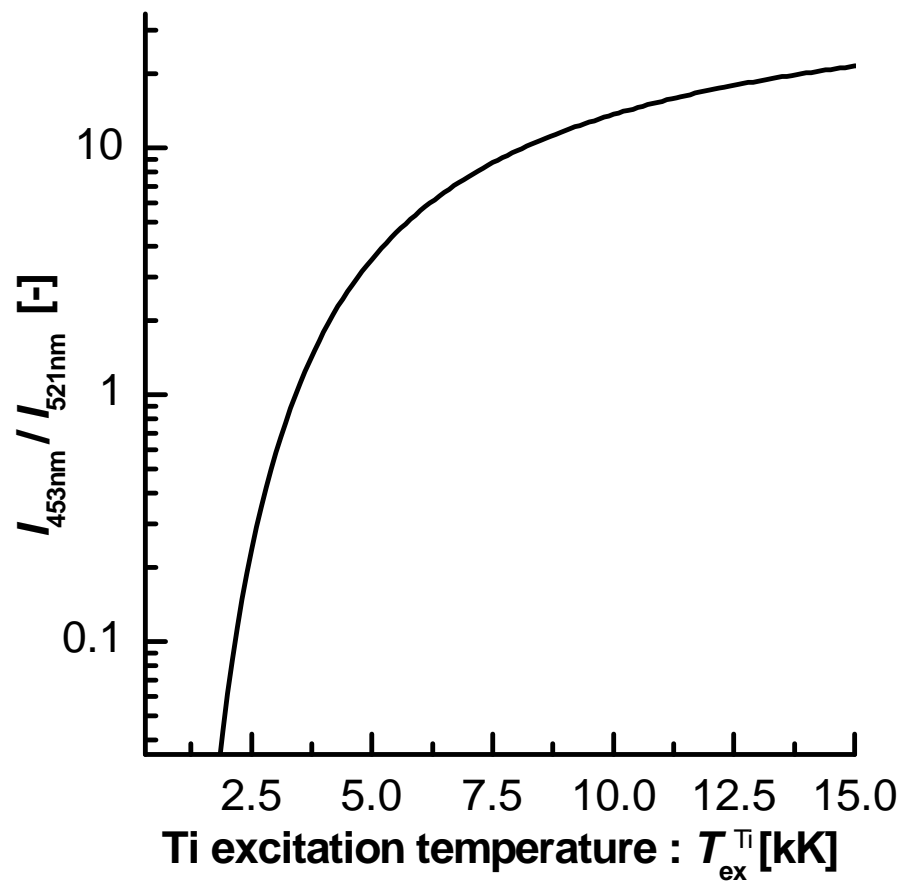

Figure 5. Relation between $I_{453} / I_{521}$ and the Ti excitation temperature. 


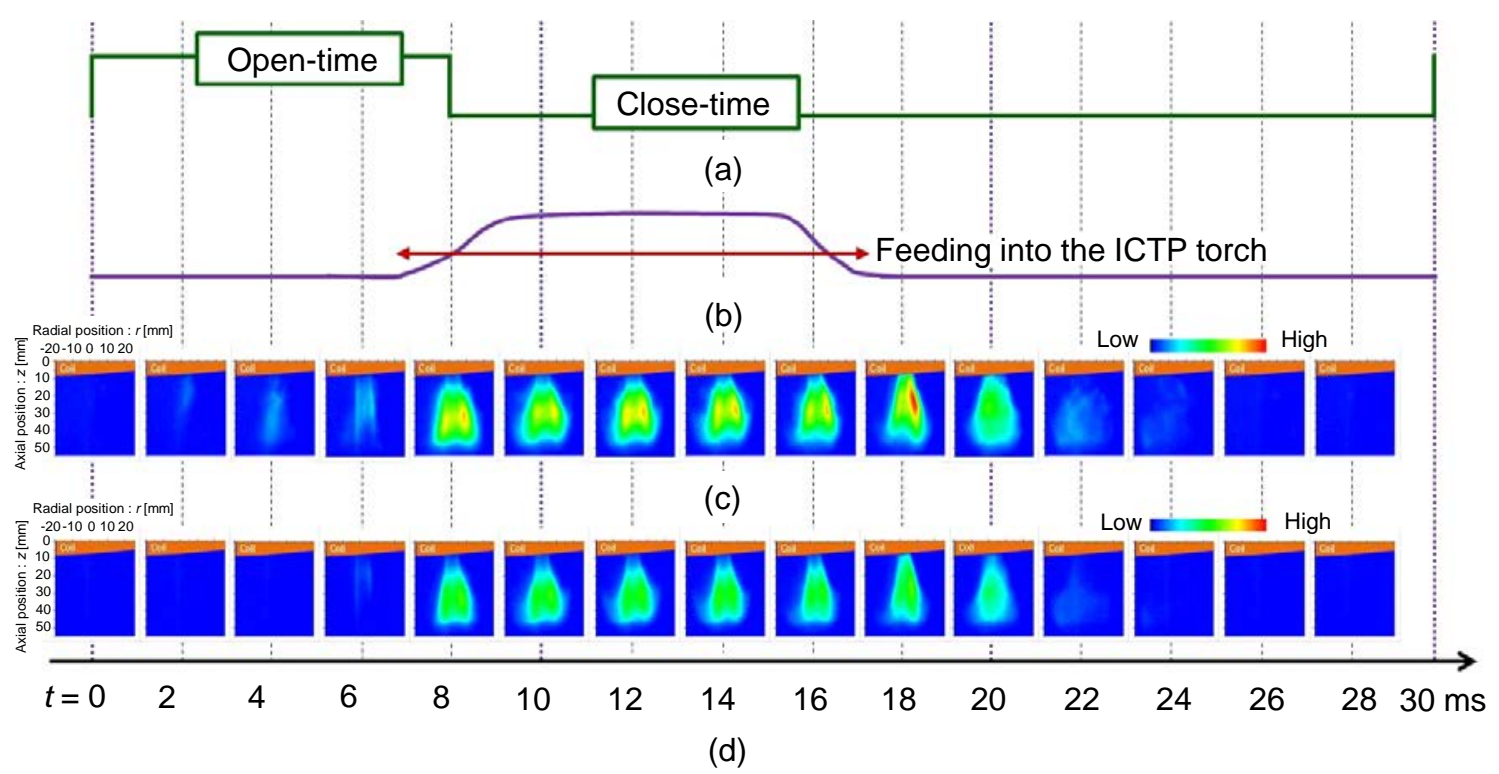

Figure 6. 2-D OES results for two Ti atomic lines. (a) High-speed solenoid valve open-close signal. (b) Estimated actual feedstock injection timing into the ICTP torch. (c) Ti I radiation intensity at $453.32 \mathrm{~nm}$ wavelength. (d) Ti I radiation intensity at $521.04 \mathrm{~nm}$ wavelength. 


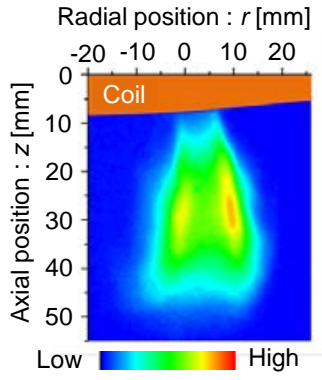

(a)

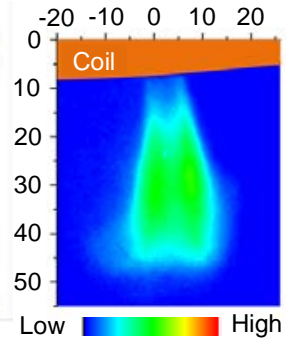

(b)

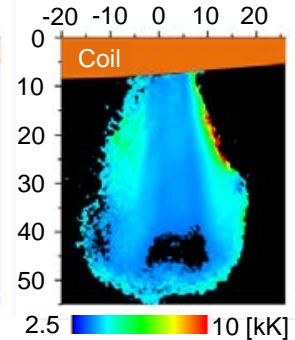

(c)

Figure 7. Comparison between Ti I radiation intensities and estimated Ti excitation temperature distribution at $t=16 \mathrm{~ms}$. (a) $\mathrm{Ti} \mathrm{I}$ radiation intensity at $453.32 \mathrm{~nm}$ wavelength. (b) Ti I radiation intensity at $521.04 \mathrm{~nm}$ wavelength. (c) 2-D distribution of Ti excitation temperature. 


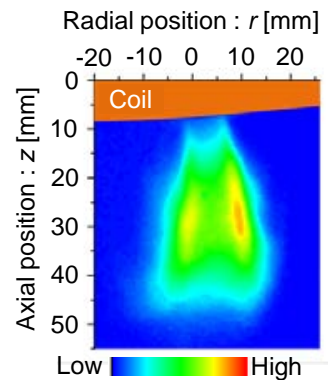

(a)

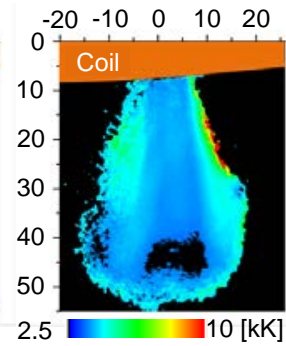

(b)

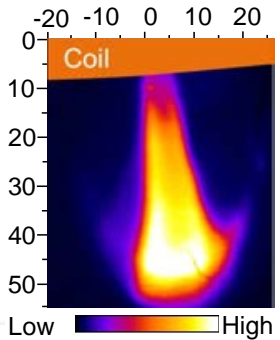

(c)

Figure 8. Comparison between $\mathrm{Ti} \mathrm{I}$ and $\mathrm{TiO}$ radiation intensities and estimated $\mathrm{Ti}$ excitation temperature distribution at $t=16 \mathrm{~ms}$. (a) Ti I radiation intensity at 453.32 $\mathrm{nm}$ wavelength. (b) 2-D distribution of Ti excitation temperature. (c) TiO radiation intensity obtained from our earlier work [31]. 


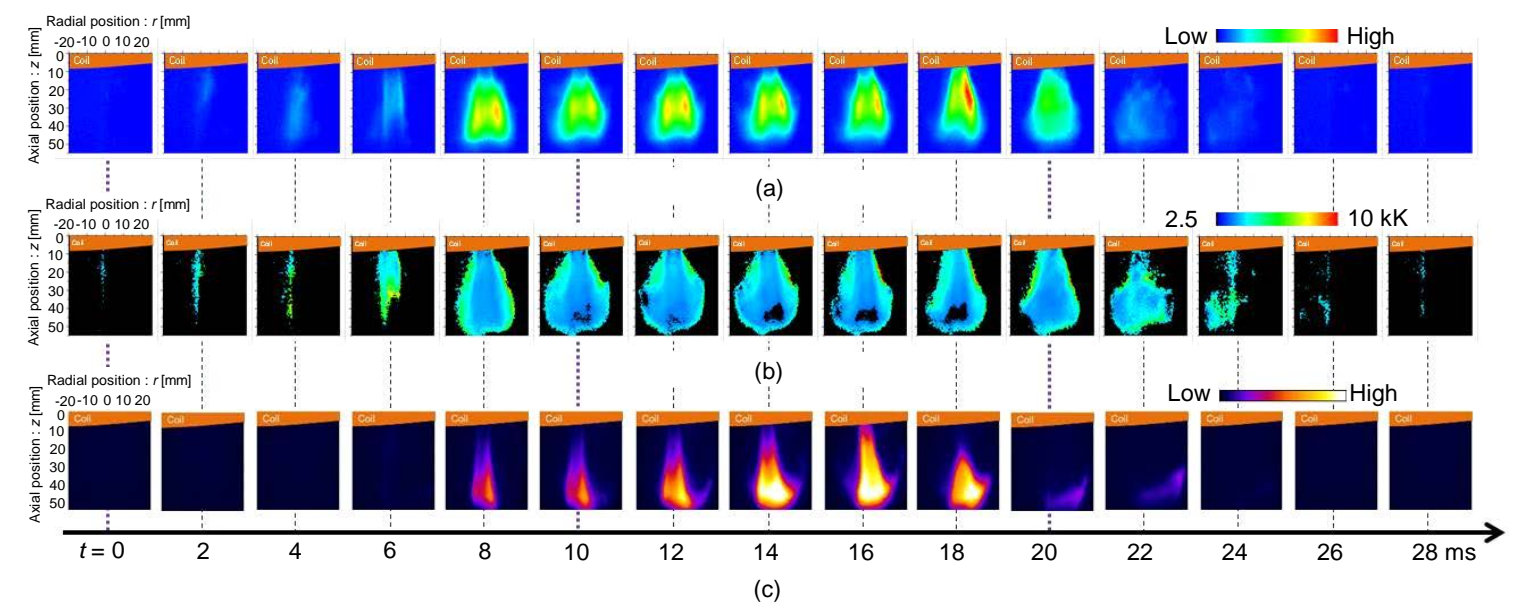

Figure 9. Comparison between 2-D OES results and estimated Ti excitation temperature distribution. (a) Ti I radiation intensity at $453.32 \mathrm{~nm}$ wavelength. (b) 2-D distribution of $\mathrm{Ti}$ excitation temperature. (c) TiO radiation intensity obtained from our earlier work [31]. 


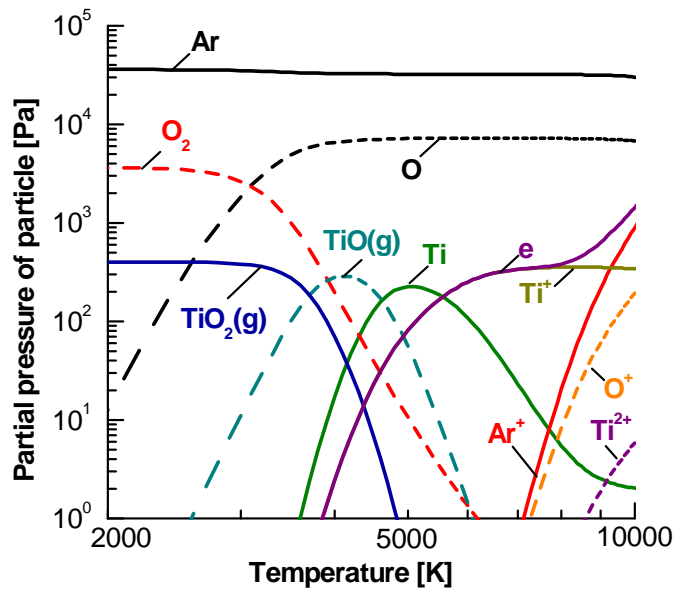

(a)

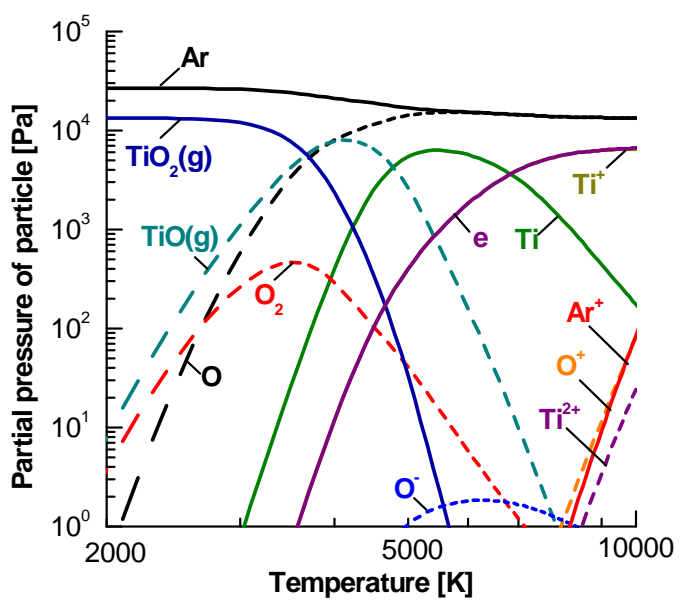

(b)

Figure 10. Equilibrium particle compositions for the $\mathrm{Ar}-\mathrm{O}_{2}$-Ti system: (a) $89 \% \mathrm{Ar}-$ $10 \% \mathrm{O}_{2}-1 \% \mathrm{Ti}$, and (b) $50 \% \mathrm{Ar}-25 \% \mathrm{O}_{2}-25 \% \mathrm{Ti}$. 


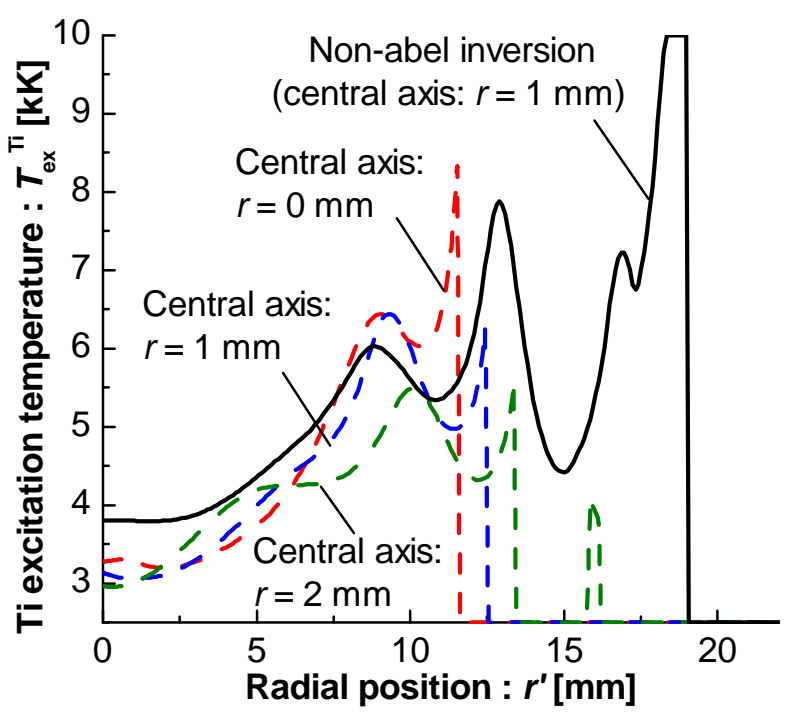

Figure 11. Estimation result of Ti excitation temperature with Abel inversion at $z=20 \mathrm{~mm}$. 


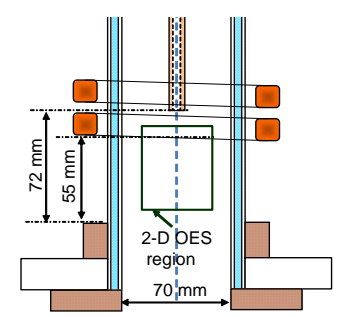

(a)

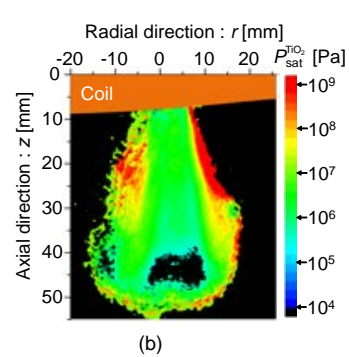

(b)

Figure 12. Estimation result of $\mathrm{TiO}_{2}(\mathrm{~g})$ saturation vapour pressure in the ICTP torch. 